\title{
ALGUMAS REFLEXÕES ACERCA DOS ESTUDOS DE LETRAMENTO E GÊNEROS TEXTUAIS/DISCURSIVOS COMO POSSIBILIDADES PARA A FORMAÇÃO DO PROFESSOR DE LÍNGUA
}

\author{
SOME REFLECTIONS ABOUT LITERACY AND TEXTUAL/DISCURSIVE GENRES \\ STUDIES AS POSSIBILITIES FOR LANGUAGE TEACHER FORMATION
}

\author{
Marcos Baltar \\ Professor/pesquisador no programa de Pós-Graduação em Linguística - UFSC \\ Milene P. Loio \\ Mestranda do Programa de Pós-Graduação em Linguística - UFSC \\ M. Letícia Naime-Muza \\ Mestranda do Programa de Pós-Graduação em Linguística - UFSC \\ João Prilla \\ Mestrando do Programa de Pós-Graduação em Linguística - UFSC
}

\begin{abstract}
Resumo
Os processos de letramento são práticas sociais que envolvem a leitura e escrita de diferentes gêneros textuais/discursivos, a partir de sua funcionalidade em cada cultura e ocorrem informalmente, no entorno familiar, bem como em outros lugares da sociedade; e, formalmente, na escola e na universidade. Com a difusão dos estudos sobre letramento e sobre os gêneros textuais, por meio de documentos oficiais (PCN, Documentos de área das Secretarias Estaduais e Municipais) o professor de língua se vê diante de uma nova realidade adentrando as escolas. A partir dessas referências, caberia a ele organizar seu trabalho em torno de práticas de letramento com o intuito de formar indivíduos leitores e escritores capazes de agir em sociedade e de refletirem sobre a língua em uso. Assim, na sociedade grafocêntrica contemporânea nos perguntamos, qual o significado de ser professor de língua / linguagem? Para tentar responder a essa pergunta complexa, o presente artigo propõe, impulsionado pelos estudos de letramento e gêneros textuais / discursivos, reflexões acerca da identidade do professor de língua e linguagem enquanto formador de sujeitos críticos e reflexivos, por meio de abordagens que abarcam currículo e formação de professores, oralidade e escrita, multimodalidade e gêneros textuais / discursivos.
\end{abstract}

Palavras-chave: Formação de professores. Letramentos. Gêneros textuais/discursivos. Currículo. Multimodalidade.

\begin{abstract}
The processes of literacy are social practices that involve reading and writing of different kinds of textual / discursive genres, from its functionality in every culture and occurs informally in familiar surroundings, as well as anywhere in society, and formally in school and university. With the spread of literacy studies about textual genres through official documents (PCN, Documents of State and Municipal Secretaries), the language teacher is faced with a new reality entering the schools. From these references, it would be up to organize his/her work around literacy practices in order to form readers and writers able to act in society and reflect on the language in
\end{abstract}


use. Thus, in contemporary society centered in writing skills we ask ourselves, what is the meaning of being a language teacher ? To try to answer this complex question, this article proposes, driven by studies of literacy and textual/discursive genres, reflections on the identity of the language teacher as a former of critical and reflexive subjects, through approaches that cover the curriculum and teacher training, orality and writing, multimodality and textual / discursive genres.

Keywords: Teacher formation. Literacies. Textual/discursive genres. Curriculum. Multimodality.

\section{INTRODUÇÃO}

Estamos buscando nesse texto refletir sobre temas que nos apontem algum sinal de resposta a uma questão sempre muito exigida a todos nós que trabalhamos no campo da linguística aplicada: o que representa ser professor de português no Brasil hoje? Essa é uma pergunta essencial, mas que parte do universo de muitas outras relacionadas à prática desse profissional nas escolas brasileiras e a sua formação nos "bancos universitários”. Essas questões dizem respeito ao contexto de trabalho em que o professor se insere, às adversidades que ele enfrenta no dispositivo escolar, entre outras que buscam entender como é possível pensarmos a identidade do profissional responsável pelo trabalho com a língua e com as múltiplas linguagens, na educação básica e profissional, um docente encarregado de formar sujeitos críticos e reflexivos capazes de agir conscientemente na sociedade grafocêntrica contemporânea.

Temos entendido que o professor de português, formado no paradigma tradicional, poderia dar espaço, na escola, para um outro profissional que atuaria mais como um agente de letramento do que como um guardião da língua materna (BALTAR, 2010). Esse agente de letramento, parafraseando Kleiman (2005), ao contrário de um superprofessor seria um organizador de atividades de linguagem que descortinassem aos estudantes cenários mais aprazíveis para o estudo das linguagens na escola; capaz de coordenar trabalhos com os usos sociais da escrita, discutindo com seus alunos novas práticas de linguagem que permitissem a mobilização de novos gêneros textuais/discursivos, orais, escritos verbo-visuais, multissemióticos no ambiente discursivo escolar. Entretanto, para que seja viável a emersão desse ethos profissional é necessário que a questão seja discutida e enfrentada desde a formação inicial nos cursos de letras de nossas universidades.

Orientados por alguns dos estudiosos que vêm refletindo acerca do currículo (STREET, 2003), da oralidade e da escrita (KLEIMAN, 2002; MARCUSCHI, 2008), da multimodalidade (KRESS, 1996; 2003), dos gêneros textuais / discursivos (BALTAR, 2006; 2009) e principalmente pelos estudos de letramento (GEE, 2008; KLEIMAN, 2007; STREET, 2003) propomos, no desenrolar desse artigo, reflexões iniciais acerca desses fatores, que a nosso ver, podem apontar caminhos interessantes no ensino de língua portuguesa da educação básica.

Para efeito de sistematização da reflexão, organizamos esse artigo em três tópicos que problematizam questões de currículo e de conteúdos; questões que afetam ensino da 
oralidade na escola e, por fim o trabalho com gêneros verbo-visuais ou multimodais ${ }^{1}$ e iniciaremos a discussão a partir de problemas ligados a formação inicial e continuada do professor de língua materna.

\section{FORMAÇÃO INICIAL E CONTINUADA DO PROFESSOR: CURRÍCULOS E CONTEÚDOS}

Atualmente é exigido do professor, enquanto profissional da linguagem, uma compreensão refinada acerca do dispositivo escolar e dos processos de letramento situado ${ }^{2}$, para que ele possa agir no contexto de situação de uso social da escrita.

É preciso salientar, entretanto, que os debates que circulam no âmbito acadêmico ainda se diferenciam muito daqueles que estão presentes no cotidiano escolar. Se trabalharmos com o intuito de desnaturalizar algumas práticas anacrônicas na escola básica, tais como o ensino desmedido da gramática normativa e o ensino das habilidades de leitura e escrita descontextualizadas - perspectiva que mantém a escola no paradigma do letramento autônomo (STREET, 1984) - então, precisamos urgentemente repensar os cursos de formação inicial e continuada dos professores. Para Street (2003), os trabalhos com o letramento têm falhado porque o que prevalece é um conceito dominante de letramento que parte da mera aplicação. $\mathrm{O}$ autor assim explica:

Para os profissionais do campo do letramento e desenvolvimento, é importante engajar-se igualmente nos debates teóricos e conceituais que estejam sendo discutidos aqui, desafiando o conceito dominante sobre o trabalho em letramento, que o considera apenas aplicado, óbvio, e sem precisar desse tipo de teoria. A teoria é para os profissionais que trabalhem na área, e não simplesmente para os teóricos. É precisamente a falta dessa atenção explícita à teoria, eu argumento, que vem levando a tantos fracassos no desenvolvimento de programas de letramento: por trás da naturalização do ensino e do aprendizado, esgueiraram-se pressões ideológicas e dogmas políticos, freqüentemente coloniais, mas também urbanos/rurais, ou baseados em conflitos e hierarquias étnicos locais (STREET, 2003, p. 6-7).

A partir dessa ideia da desnaturalização das práticas tradicionais nas agências de letramento formais (escola / academia), gostaríamos de chamar a atenção para aquilo que acreditamos ser um dos problemas principais que poderiam ser enfrentados nesses lugares sociais contemporaneamente: a revisão de currículos de Letras na academia e a revisão dos conteúdos de língua portuguesa nas escolas.

\footnotetext{
${ }^{1}$ As contribuições que trazemos nesse texto estão associadas a discussões que estão sendo enfrentadas em três projetos de pesquisa em andamento, no Programa de Pós-graduação em Linguística da Universidade Federal de Santa Catarina, cujo foco é a formação de professores na perspectiva dos estudos de letramento e dos gêneros textuais/discursivos.

2 Acerca do letramento situado Tardif (2002), explica que os professores possuem saberes profissionais como saberes situados que se formam em função de uma determinada situação de trabalho e só possuem sentido a partir dessa relação, ou seja, além dos saberes adquiridos pelo professor em sua formação, há também os saberes formados pela experiência em um contexto de trabalho. O que ocorre na formação dos professores é que há lacunas com relação às práticas pedagógicas e as abordagens teóricas enfatizadas não atendem às situações experienciadas pelos professores no cotidiano escolar.
} 
Em âmbito acadêmico de nível superior é possível dizer que alguns currículos ainda vêm se preocupando muito mais em reproduzir modelos científicos que seguem uma lógica positivista, momento em que a linguística buscava afirmar seu espaço no campo das ciências humanas. A academia continua contribuindo, desse modo, para ampliar a lacuna entre as teorias do campo dos estudos da linguagem, mais precisamente dos letramentos, e a prática docente de ensino de língua.

No intuito de refletir sobre essas questões, Kleiman (2007, p. 4) postula que "assumir o letramento como objetivo do ensino no contexto dos ciclos escolares implica adotar uma concepção de uso social da escrita”. Para que se possa assumir essa concepção é necessário rediscutir o papel do professor, sua formação inicial e continuada, nos dispositivos universidade e escola. Dessa forma, defendemos, primeiramente, um curso com ênfase na formação de professores e nos estudos de letramento, pois este poderia funcionar "como um lugar para desnaturalização, para a efetivação de um paulatino processo de desideologização da leitura e da escrita” (KLEIMAN, 2007, p.4).

Para estipular os conteúdos no âmbito da educação básica, bem como da universidade, programas de cunho federal têm sido criados como fonte impulsionadora, como o ENEM (Exame Nacional do Ensino Médio). Nos últimos anos, com a valorização do ENEM iniciamos um novo movimento de deslocamento das lógicas curriculares em que os conteúdos descontextualizados têm sido substituídos por novos paradigmas de linguagem, principalmente àqueles que dão ênfase ao desenvolvimento de competências. São ainda passos tímidos para enfrentar o problema.

A partir da difusão dos estudos de autores como Freire (1967) e Street (1984), Kleiman (1995), Soares (1998), Rojo (2009), Oliveira (2010), entre outros, tornou-se possível propor a ressignificação das práticas com a linguagem na escola, acenando para a necessidade de romper com "modelo asséptico de letramento autônomo escolar, considerado como mecânico, individualizado, centrado no domínio da escrita como tecnologia desvinculada da vida social” (BALTAR, 2009, p. 19).

Já na universidade, a maior parte dos cursos de Letras está estruturada na lógica da formação comum para licenciatura e bacharelado, o que significa dizer que até o quinto ou sexto semestre os estudantes cursam uma carga exaustiva de disciplinas comuns a essas duas especificidades (média de cinco disciplinas por semestre). Não bastasse esse problema de falta de foco, até a metade do curso de formação dos futuros profissionais (bacharéis e professores), os currículos costumam estruturar-se em torno de um grupo de mais ou menos cinqüenta disciplinas, distribuídas entre as áreas de literatura e linguística, quase que equanimente.

O que aparentemente sugere ser algo razoável, quando é colocado sob uma análise mais minuciosa revela problemas importantes. Uma questão interessante seria pensar sobre a demanda da educação básica em relação a essas duas áreas. Se analisarmos os editais de concurso público teremos dificuldade em encontrar essa paridade entre vagas para professor de língua portuguesa e para literatura. Mesmo assim, a maioria dos cursos organizam-se, via de regra, ofertando cerca de cinquenta por cento de disciplinas do campo da literatura e da teoria literária, e outros cinquenta por cento de disciplinas do campo da linguística, distribuídas entre as duas vertentes, a saber: a linguística dita "hard" e a linguística aplicada. Da primeira vertente é comum estudar-se fonética, 
fonologia, morfologia, sintaxe, semântica; além de história da língua e estudos gramaticais; da segunda vertente é comum estudar-se leitura e produção textual acadêmica, linguística textual e linguística aplicada, além de, eventualmente, análise do discurso e teoria da enunciação. O currículo se completa com disciplinas eletivas e com as práticas, além dos estágios em licenciatura, os quais na maioria dos cursos são ministrados por professores do departamento da educação ${ }^{3}$.

Sabemos que tais reflexões são ainda iniciais, mas as pontuamos entendendo a necessidade do ensino na universidade contemplar os estudos de letramento para que na educação básica, o objetivo seja o do estudante poder mobilizar sua língua em sociedade, portanto é preciso uma revisão criteriosa e urgente dos projetos políticospedagógicos dos cursos de Letras e seus respectivos currículos, bem como uma revisão dos projetos políticos-pedagógicos das escolas e dos conteúdos programáticos da disciplina de língua portuguesa. Para encaminhar essa revisão sugerimos que as reflexões busquem respostas a três questões: a) Que disciplinas na universidade dariam conta da formação de um profissional de linguagem que possa coordenar na escola um trabalho com as implicações dos usos sociais da escrita na sociedade grafocêntrica contemporânea? b) No contexto escolar, por que ensinar determinados conteúdos e não outros e qual o perfil do egresso da educação básica, levando em consideração essas escolhas feitas? E, por fim, c) Como organizar o trabalho, ou ainda, como ensinar a partir das bases teórico-metodológicas do campo dos estudos de letramento e dos gêneros textuais/discursivos? Concentraremo-nos, adiante, nesta última questão colocada a fim de apresentar algumas proposições acerca do trabalho com a oralidade e também do ensino de gêneros textuais multimodais, mais especificamente, o mangá, sob a perspectiva teórica dos estudos de letramento.

\section{A ORALIDADE E A ESCRITA COMO ATIVIDADES COMPLEMENTARES}

Como já dissemos até aqui, refletindo sobre a necessidade de se repensar a formação inicial, continuada, e ainda, os currículos na escola e na academia, queremos reafirmar que o ensino de línguas a partir da perspectiva dos gêneros textuais/discursivos tem sido um desafio para as escolas brasileiras, apesar do PCN (Parâmetros Curriculares Nacionais) apontarem as diretrizes curriculares para o ensino e aprendizagem nessa perspectiva.

Os PCNs propõem o uso da linguagem em diferentes situações de comunicação, para possibilitar a inserção social e ampliar, consequentemente, as condições de participação dos educandos no exercício de sua cidadania. Para isso a escola deve pensar, organizar e preparar um conjunto de atividades que, progressivamente e correlacionadas, possibilite ao aluno "utilizar a linguagem na escuta e produção de textos orais e na leitura e produção de textos escritos de modo a atender a múltiplas demandas sociais, responder a diferentes propósitos comunicativos e expressivos, e considerar as diferentes condições de produção do discurso" (PCN, 1998, p. 32). Apropriamo-nos dos conteúdos ou objetos de conhecimento quando os transformamos em conhecimentos próprios, ou seja, quando mobilizamos conscientemente o conhecimento ao interagirmos com o outro, pois “é nas práticas sociais, em situações linguisticamente significativas, que se

\footnotetext{
${ }^{3}$ A base para essas afirmações é um estudo em andamento sobre o currículo do curso de Letras da Universidade Federal de Santa Catarina e a formação inicial do professor.
} 
dá a expansão da capacidade de uso da linguagem e a construção ativa de novas capacidades que possibilitam o domínio cada vez maior de diferentes padrões de fala e de escrita” (PCN, 1998, p. 34).

Deste modo, segundo Kleiman (2002), a prática oral do professor é um fator importante para a inserção dos alunos nas práticas sociais de uso não somente em se tratando de escrita como também de oralidade. O professor deve conhecer seu aluno, a comunidade e seu entorno (local, social e cultural) que determinará a inter-relação, comunicação, interpretação e negociação de sentidos do processo comunicativo. A concepção de competência comunicativa deve levar em conta a dimensão social no agir interacional. Nesse sentido, o ensino de línguas deve se materializar a partir dos gêneros textuais pensando no uso da linguagem em contextos de sentido, em práticas situadas e na reflexão sobre a língua oral e escrita. Os elementos que determinam e integram a competência comunicativa são os aspectos relativos à possibilidade, adequação, viabilidade e realização da linguagem segundo as normas, regras e parâmetros do evento de fala, ou de letramento, numa situação comunicativa (Kleiman, 2002). Aqui podemos distinguir os conceitos relacionados à competência comunicativa e discursiva sendo que aquela equivale à capacidade de alguém se comunicar com o outro e esta à capacidade de produzir enunciados de um discurso específico em uma situação igualmente específica. Assim,

Competência discursiva é um amálgama de capacidades que o usuário
de uma língua natural atualiza e concomitantemente desenvolve,
quando participa das atividades situadas de linguagem que ocorrem
nos diversos ambientes discursivos da sociedade. Além de
capacidades linguísticas, textuais e comunicativas, para viver de forma
autônoma, esse usuário necessita compreender as diferentes formações
discursivas e os respectivos discursos que compõem os ambientes
discursivos dessa sociedade. Dominar a maior gama possível dos
gêneros textuais, orais e escritos, disponível no inventário construído
socioistoricamente corrobora para o usuário desenvolver sua
competência discursiva, já que é por intermédio dos gêneros textuais
que se dá toda interação sociodiscursiva. A competência discursiva do
usuário de uma língua abarca todas essas capacidades, é dinâmica e
está em constante desenvolvimento, pois é atualizada a cada momento
em que ele participa de uma atividade situada de linguagem, de forma
ativa e responsiva (BALTAR, 2006, p.48).

Essa competência comunicativo-discursiva permite ao participante de um evento de fala ou letramento usar a linguagem em uma determinada situação comunicativa e em um determinado contexto social. Os parâmetros do possível, do adequado ou apropriado, do viável e do realizável (da realização) envolvem conhecimentos e capacidades de uso da linguagem aplicados aos contextos interacionais. Uma dimensão que deve ser contemplada na competência comunicativo-discursiva:

[...] são os determinantes socioistóricos, próprios de uma concepção social e interacional da linguagem, em que o social já está inscrito e, portanto, constituindo o sujeito. Esse conhecimento sobre os usos da linguagem está integrado no conceito de gênero discursivo de Bakhtin (1953), cujo funcionamento numa situação comunicativa integra os aspectos linguístico-textuais, cognitivos, sociointeracionais, históricos 
e culturais relevantes para usar a linguagem. (...) A heterogeneidade dos contextos construídos na interação e as relações interdiscursivas mostram as possibilidades de reproduzir, criar ou subverter os parâmetros da situação, com isso evitando qualquer possibilidade de determinismo (KLEIMAN, 2002, p. 27-8).

Observamos que, conforme afirma Marcuschi (2008), hoje, se não podemos mais separar fala e escrita, pelo menos não podemos mais observar tão distintamente as semelhanças e diferenças entre fala e escrita, pois há uma nova concepção de língua e texto, um novo objeto de ensino considerando língua e texto como um conjunto de práticas sociais.

Escrita e fala, além de modos de representação imagética, organizam quase todas as práticas sociais convencionando-se chamá-las de práticas de letramento ou práticas discursivas, de modo que estão diretamente relacionadas à realidade do sujeito:

A escrita é usada em contextos sociais básicos da vida cotidiana, em paralelo direto com a oralidade. Estes contextos são, entre outros: o trabalho, a escola, o dia-a-dia, a família, a vida burocrática, a atividade intelectual. Em cada um desses contextos, as ênfases e os objetivos do uso da escrita são variados e diversos. Inevitáveis relações entre escrita e contexto devem existir, fazendo surgir gêneros textuais e formas comunicativas, bem como terminologias e formas típicas. Seria interessante que a escola soubesse algo mais sobre essa questão para enfrentar sua tarefa com maior preparo e maleabilidade, servindo até mesmo de orientação na seleção de textos e definição de níveis de linguagem a trabalhar (MARCUSCHI, 2008, p. 19).

Partindo de uma concepção sociointeracionista de linguagem, as relações entre fala e escrita devem ser tratadas como um contínuo determinado pelos usos sociais situados da escrita em uma sociedade como a nossa, grafocêntrica. Desde um bilhete escrito a uma conferência oral, são inúmeras as possibilidades de interação mediadas por diferentes gêneros orais e escritos, que organizam diferentes práticas discursivas em sociedade ${ }^{4}$.

Assim, é necessário dizer que, fala e escrita não possuem supremacia uma sobre a outra. Isto quer dizer que não há propriedade negativa ou privilegiada de uma em relação à outra: oralidade e escrita constituem-se como forma de compreensão e expressão complementares na interação humana. Nesse sentido, é possível não só ensinar a escrever textos, como também a se expressar oralmente em situações públicas e extraescolares, quando se proporciona na escola múltiplas ocasiões de escrita e de fala, sem que cada produção se transforme, necessariamente, no objeto de ensino sistemático. Isso se torna uma realidade, ao criarmos um contexto de produção que permite aos alunos apropriarem-se das noções, das técnicas e dos instrumentos, necessários ao desenvolvimento de expressão oral e escrita, em situações diversas de comunicação. Tanto a modalidade oral quanto a escrita cumprem papéis distintos em seus diferentes

\footnotetext{
${ }^{4}$ Segundo Kleiman (2005, p. 59) A compreensão do funcionamento das modalidades oral e escrita em sociedade como um contínuo foi primeiramente aludida no texto Integration and involvement in speakin, writing, and oral literature, do lingüista americano Wallace Chafe, publicado em 1982, no livro Spoken and written language: exploring orality and literacy, organizado pela sociolinguista americana Déborah Tannen.
} 
contextos de uso e são imprescindíveis na sociedade atual, podendo ser trabalhadas sistematicamente na escola para que os alunos desenvolvam sua competência discursiva.

\section{LETRAMENTO VISUAL E MULTIMODALIDADE: NOVAS MOTIVAÇÕES SOCIAIS E POSSIBILIDADES DE ENSINO}

Refletimos, nas seções anteriores, sobre algumas questões referentes à identidade do professor de língua e linguagem, enquanto formador de sujeitos críticos e atuantes, e sua transição para um novo profissional no ensino de língua e linguagem: o agente de letramento. Abordamos a necessidade de uma mudança em muitos aspectos dos currículos atuais do ensino de língua materna, dialogamos sobre a formação inicial e continuada de professores, e também sobre temáticas mais pontuais, como o letramento e o espaço da oralidade e escrita no ensino da língua. Esse profissional nomeado agente de letramento (KLEIMAN, 2005) seria um organizador de atividades de linguagem que descortinassem aos estudantes cenários mais aprazíveis para o estudo das linguagens na escola; um sujeito capaz de coordenar trabalhos com os usos sociais da escrita, discutindo com seus alunos novas práticas de linguagem, que permitissem a mobilização de novos gêneros textuais/discursivos, orais, escritos, verbo-visuais, multissemióticos no ambiente discursivo escolar. Nesta seção, faremos uma breve reflexão sobre o letramento visual e sobre textos multimodais - elementos de ampla circularidade nas esferas sociais, mídia, televisão e, sobretudo na internet - geradores de novas motivações sociais, tendo em vista suas implicações e possibilidades no ensino e aprendizagem de língua.

Percebemos que atualmente os novos estudos do letramento têm-se voltado em especial para os letramentos locais ou vernaculares, de maneira a dar conta da heterogeneidade das práticas não valorizadas e, consequentemente, pouco investigadas.

Podemos dizer ainda que, por efeito da globalização, o mundo mudou muito nas duas últimas décadas. É especialmente importante destacar as mudanças relativas aos meios de comunicação e à circulação da informação no âmbito de exigências de novos letramentos. O surgimento e a ampliação contínua de acesso às tecnologias digitais da comunicação e da informação implicaram algumas mudanças que ganham importância na reflexão sobre os letramentos: a intensificação e a diversificação da circulação nos meios de comunicação analógicos e digitais (os quais distanciam-se hoje dos meios impressos) ocasionando maneiras de ler, de produzir e de fazer circular textos nas sociedades (CHARTIER, 1997); a diminuição das distâncias espaciais (geográficas e ou culturais), desenraizando as populações e desconstruindo identidades; a diminuição das distâncias temporais ou a contração do tempo; a multissemiose ou a multiplicidade de modos de significar que as possibilidades multimidiáticas e hipermidiáticas do texto eletrônico trazem para o ato de leitura (é preciso relacionar o texto verbal com um conjunto de signos de outras modalidades de linguagem); o fato de os textos multissemióticos terem ultrapassado os limites dos ambientes digitais e invadido também os impressos.

As mudanças na escola- principalmente a pública- sobretudo na universalização e ampliação do acesso à educação tem impactos visíveis nos letramentos escolares: o 
ingresso de alunos e de professores das classes populares nas escolas públicas trouxe para a escola letramentos locais ou vernaculares antes desconhecidos e ainda hoje ignorados. Isso cria uma situação de conflito entre práticas letradas valorizadas e não valorizadas na escola (KLEIMAN, 1995; 1998).

Hamilton (2002) aponta para o fato de que muitos dos letramentos que são influentes e valorizados na vida cotidiana das pessoas e que têm ampla circulação são também ignorados e desvalorizados pelas instituições educacionais. Um exemplo que ilustra tal afirmação são as redes sociais e informais que sustentam essas práticas letradas: as redes e comunidades virtuais de que jovens e adolescentes de todas as classes participam permanecem desconhecidas e apagadas nas escolas, quando não têm seu acesso proibido, como é o caso da proibição de acesso ao Orkut, Facebook, Twitter, MSN em muitas escolas e universidades conectadas.

Dialogando com Rojo (2009, p. 106-107) a escola de hoje é um universo onde convivem letramentos múltiplos e diferenciados, cotidianos e institucionais, valorizados e não valorizados, locais e globais, vernaculares e universais, sempre em contato e em conflito, sendo alguns rejeitados ou ignorados e apagados e outros constantemente enfatizados. Nessa perspectiva, o que significa trabalhar a leitura e a escrita para o mundo contemporâneo? Como delinear "políticas de letramento ao longo da vida" (HAMILTON, 2002) que sustentem e desenvolvam, efetivamente, os recursos, processos e metas que existem e são requeridos na vida social atualmente?

Um dos objetivos principais da escola do século XXI é justamente possibilitar que os alunos participem das várias práticas sociais que se utilizam da leitura e escrita letramentos - na vida urbana, de maneira ética, crítica e democrática. Para tanto, é necessário que a educação leve em conta os letramentos múltiplos, considerando os letramentos das culturas locais de seus agentes - professores, alunos e comunidade escolar - e colocando-os em contato com os letramentos valorizados, institucionais e universais. Além disso, deve considerar os letramentos multissemióticos exigidos pelas interações contemporâneas, ampliando a noção de letramentos para o campo da imagem, do som, de outras semioses que não somente a escrita. O conhecimento e as capacidades relativas a outros meios semióticos estão ficando cada vez mais necessários no uso da linguagem, tendo em vista os avanços tecnológicos. As cores, as imagens, os sons, o design, o layout, etc., que estão disponíveis na tela do computador e em muitos materiais impressos, têm transformado o letramento autônomo em um tipo de letramento insuficiente para dar conta dos letramentos necessários para agir na vida contemporânea.

Os gêneros multimodais referem-se àqueles que utilizam além da linguagem verbal uma linguagem não-verbal que ao se articularem geram possibilidades de sentido (KRESS e VAN LEEUWEN, 2001). Com isso, devido à mudança nas formas de impressão e visualização dos textos no ciberespaço, e também, a existência da possibilidade de articulação entre texto e imagem na mídia televisiva e cinematográfica, o papel do leitor sofre significativas modificações, visto que se torna primordial para uma leitura eficaz e crítica que o indivíduo seja capaz de reagrupar suas estruturas sociodiscursivas para conseguir interpretar e entender esses tipos de textos. 
Coêlho (2010) aponta que a linguagem em seus aspectos de representação da vida coevoluiu com a maneira de construção da sociedade contemporânea. Dessa maneira, cultura, história e linguagem se relacionam e se transformam constantemente, na medida em que representam o agir, o pensar, o ser e o sentir das pessoas, simultaneamente, multifacetado e individual que produz a realidade tanto cotidianamente quanto nos textos multimodais/multissemióticos.

A partir da entrada das novas tecnologias nas instituições de ensino, com muita facilidade se criam novas imagens, novos layouts, bem como se divulgam tais criações para uma ampla audiência. Todos os recursos utilizados na elaboração dos gêneros textuais exercem uma função retórica na construção de sentidos dos textos. De acordo com Dionísio (2006), cada vez mais se observa a combinação de material visual com a escrita; vivemos sem dúvida, numa sociedade cada vez mais visual.

Bakhtin (2003) postula que a linguagem é concebida como um mecanismo de interação social que tanto reflete quanto retrata a vida cotidiana e que sempre é dialógica. Desse modo, os gêneros textuais ultrapassam as manifestações discursivas e sociocognitivas dos tratados político-ideológicos que moldam e constroem as relações entre os indivíduos, do mesmo modo que determinam os papéis sociais a serem seguidos nas diferentes situações do viver em sociedade.

O discurso verbal e não-verbal, dentro de cada gênero textual é resultado de uma ação comunicativa tanto coletiva quanto individual que se atualiza, constantemente, pelo fato da interatividade entre ficção e realidade que permite a verossimilhança. Não devemos entender tal verossimilhança como uma "xerox" exclusiva do real, mas uma possibilidade de aceitação do enredo da história, isto é, o reconhecimento das redes de significados plausíveis para a sua compreensão.

Por exemplo, a leitura do gênero mangá entre o público infanto-juvenil (bem como outros gêneros emergentes / recentes que ainda circulam na esfera escolar de maneira "clandestina”, trazidos pelo alunado que os conhece e explora cotidianamente em meios virtuais ou impressos fora da sala de aula), diante do contexto da disseminação da informação em um toque, da iconização da cultura e sua transposição para a televisão e para a tela do cinema, bem como, a sua influência na elaboração dos quadrinhos nacionais (Turma da Mônica Jovem é um exemplo desse fenômeno) e mundiais, tornase um evento de dimensão global que legitima e dissemina parâmetros de comportamento, maneiras ideológicas do pensar, do agir e do dizer de uma dada cultura (não especificamente a japonesa), ao mesmo tempo em que simboliza e reproduz os mecanismos ideológico-culturais do modelo econômico vigente. Essa cultura pop abrange uma diversidade de leitores de todas as faixas etárias (crianças, jovens e adultos) que fascinados pela sua linguagem híbrida de leitura acessível e prazerosa projetam seus sonhos e fantasias, escondem seus medos e frustrações em uma forma de entretenimento e deleite.

Por serem narrativas icônico-verbais, os mangás, ao serem lidos precisam acionar uma rede de significações sociocognitivas, o que requer que o leitor seja multiletrado para poder perceber que esse tipo de texto não é tão inocente aparenta em uma primeira leitura. E isso é uma característica constante em todos os textos multimodais, hipertextuais e multissemióticos. Para tanto, propomos a exploração desses textos nas 
escolas, ancorada em uma prática pedagógica que possibilite ao aluno, orientado pelo seu professor/agente de letramento, ser um sujeito crítico e reflexivo sobre os textos que lê e produz, para poder compreender, interpretar e ressignificar os efeitos de sentido e os significados tanto explícitos quanto implícitos constitutivos dos textos de linguagem verbal e não-verbal.

Assim, tomando novamente como exemplo a narrativa sequencial do gênero mangá, a linguagem fluida e oralizada com suporte nas imagens estilizadas é um mecanismo que seduz ao mesmo tempo que manipula discretamente seus leitores por meio dos estereótipos sociais disseminados pelos personagens dessas histórias. Nesse sentido, entendemos que esse gênero poderia se prestar a atividades de letramento escolar (multisemiótico) por se tratar de uma prática discursiva emergente relacionada à aparição de novas motivações sociais resultantes de diferentes circunstâncias de comunicação associadas à produção tecnológica, no intuito de proporcionar aos estudantes possibilidades de leituras multimodais.

\section{CONSIDERAÇÕES FINAIS}

O agente de letramento, atuando na escola, em substituição ao professor de língua portuguesa, poderia assumir a função de mediar práticas discursivas em múltiplas linguagens que possibilitassem o rompimento do contrato tácito (e vil) entre o dispositivo escolar e o modelo autônomo de letramento. Esse profissional poderia trabalhar para ampliar as redes de pertencimento de crianças, adolescentes, jovens e adultos que passam pelos dispositivos escolares, respeitando seus letramentos vernaculares, trabalhando o trânsito entre a cultura local e global, canônica e marginalizada, de modo a evitar traumas, insegurança e o medo de agir na e pela linguagem em ambientes discursivos, como o da escola.

O trabalho com a língua oral pública e formal e com gêneros textuais/discursivos multimodais, que coordenam ações em diferentes esferas da comunicação humana na vida cultural contemporânea, manifestando-se em diferentes mídias e suportes ampliaria as possibilidades de compreensão dos modos de agir na sociedade hodierna, possibilitando aos alunos que estão em fase de escolarização, uma formação mais crítica e protagonista, nos moldes que propõem, por exemplo, Freire (1981), Gee (2008), Mc Laren (1988), entre outros autores do campo do letramento crítico.

Para tanto, estamos defendendo aqui que o trabalho de formação inicial e continuada de professores deveria sofrer um reformulação importante, na direção da inserção e da problematização em seus currículos dos temas caros aos campos dos Estudos de Letramento (s) e dos Estudos dos Gêneros textuais/discursivos, primordialmente.

\section{REFERÊNCIAS}

BAKHTIN, M. Estética da criação verbal. São Paulo: Martins Fontes, 2003.

BALTAR, M. Competência discursiva e gêneros textuais: uma experiência com o jornal na sala de aula. 2. ed. Caxias do Sul, RS: Educs, 2006. 
2009.

[et al]. Rádio escolar: letramentos e gêneros textuais. Caxias do Sul: Educs,

Mídia, escola, agentes de letramento e gêneros textuais. In. SERRANI, Silvana. (Org.) Letramento, discurso e trabalho docente: uma homenagem a Ângela Kleiman. Vinhedo-SP: Editora Horizonte, 2010.

BRASIL, Parâmetros Curriculares Nacionais: primeiro e segundo ciclo do ensino Fundamental - Língua Portuguesa. Brasília: MEC/SEF, 1998.

CHARTIER, R. A aventura do livro: do leitor ao navegador. São Paulo. EDUNESP, 1998.

COÊLHO, C. T. Mangá: uma ferramenta didática para multiletramentos. Universidade Estadual de Londrina, 2010. Disponível em:

$<$ www.uel.br/.../manga_uma_ferramenta_didatica_para_multiletramentos.pdf $>$ Acesso em 23-04-2011.

DIONÍSIO, Â. P. Gêneros multimodais e multiletramento. In: KARWOSKI, A.

GAYDECZKA, [et al] (Orgs.) Gêneros textuais: reflexões e ensino. Rio de Janeiro:

Lucerna, 2006, p. 131-144.

FREIRE, P. Educação como prática da liberdade. Rio de Janeiro: Paz e Terra. 1967.

A importância do ato de ler: em três artigos que se completam. São Paulo:

Cortez, 2009[1981].

GEE, J. P. Social Linguistics and Literacies: Ideology in Discourses. Londres: taylor \& Francis, 2008.

HAMILTON, M. Sustainable Literacies and the Ecology of Lifelong Learning. In:

HARRINSON, R. R. F., [et al]. (Orgs.) Supporting Lifelong Learning, v. 1: Perspectives on Learning. Routledge: Open University Press, 2002.

KLEIMAN, Â. Os significados do letramento: uma nova perspectiva sobre a prática social da escrita. Campinas: Mercado de Letras, 1995.

. Oralidade letrada e competência comunicativa: implicações para a construção da escrita em sala de aula. Scripta, v.6. n. 11, 2002.

Preciso ensinar o letramento? Não basta ensinar a ler e escrever? Campinas:

CEFIEL, IEL, Unicamp, 2005. (Coleção linguagem e letramento em foco).

. Letramento e suas implicações para o ensino de língua materna. Signo, Santa

Cruz do Sul, v. 32, n. 53, p.1-25, dez/2007.

KRESS, G. Alfabetização na Idade Media Nova. London: Routledge Routledge, 2003. 
.; VAN LEEUWEN, T. Multimodal discourse. London: Routledge, 1996.

. Multimodal discourse: the modes and media of contemporary communication. New York: Oxford University Press, 2001.

LUYTEN, S. B. Mangá: O poder dos quadrinhos japoneses. São Paulo: Hedra, 2001.

MARCUSCHI, L. A. Da fala para a escrita: atividades de retextualização. São Paulo: Cortez, 2008.

McLAREN, P. L. Culture or Canon? Critical Pedagogy and the Political of Literacy. Havard Educational Review, 58(2), 1988.

MOSDZENSHI, L. Multimodalidade e gênero textual: analisando criticamente as cartilhas jurídicas. Recife: Editora Universitária (UFPE) / Coleção Teses, 2008.

OLIVEIRA, M. S. Gêneros textuais e letramento. Revista Brasileira de Linguística Aplicada. $\mathrm{n}^{\circ}$ 2, vol. 10, p. 325 - 346. Belo Horizonte, 2010.

ROJO, R. Letramentos múltiplos: escola e inclusão social. São Paulo: Parábola Editorial, 2009.

SOARES, M. Letramento: um tema em três gêneros. Belo Horizonte: Autêntica, (Letramento em verbete), 1998.

STREET, B. Literacy and Development: Ethnographic Perspectives (Letramento e Desenvolvimento: Perspectivas Etnográficas) Routledge: Londres, 2001. Literacy in Theory and Practice. Cambridge, MA: C.U.P., 1984. Abordagens alternativas ao letramento e desenvolvimento. Teleconferência Unesco Brasil sobre 'Letramento e Diversidade', outubro de 2003.

TARDIF, M. Saberes docentes e formação profissional. 11. ed. Petrópolis: Vozes, 2010. 